\title{
Thinking Outside Discipline Boundaries to Integrate Indian Education for All Across the Curriculum
}

\author{
Jioanna Carjuzaa \& Holly Hunts \\ Montana State University-Bozeman
}

The Montana Indian Education for All (IEFA) Act is an unprecedented reform effort 40 years in the making. In this paper we summarize the IEFA professional development opportunities provided to faculty at a land grant university in the western United States while highlighting a faculty member's personal efforts to integrate IEFA in a culturally responsive manner. We explain how, instead of limiting the transmission of ideas, expanding discipline boundaries has opened a flood-gate to new information and other ways of knowing' for the faculty member and her students.

\section{Montana's Indian Education For All Act}

I questioned why these 'trainings' were mandatory for me. Sure, I agreed that 'those' history faculty ought to do a better job teaching American Indian history and 'those' sociology faculty really ought to teach more about social justice. I understood why faculty would want to avoid lectures about American Indians. What a disaster it would be if faculty said something wrong. By design, I never said anything wrong in class about American Indians, because I never said anything at all (personal communication, 2012).

$\mathrm{M}$ ontana, located in the high plains and Rocky Mountains of the western United States borders three Canadian provinces. It is home to 12 tribes on seven reservations, each of which is a sovereign nation and each proudly supports a Tribal College. In addition, the Little Shell Band of Chippewa, who are landless, call northern and central Montana home. In our context, we use the terms American Indians, Native Americans, and Indians interchangeably to describe the Indigenous population which constitutes $6.4 \%$ of the total state population and $11.8 \%$ of the K-12 student population, a percentage more than 10 times the national average of American Indian students attending public elementary and secondary schools throughout the U.S. (OPI, 2010).

The audacious reform effort described here is known as the Indian Education for All (IEFA) Act. Now a funded reality, IEFA incorporates the teaching of American Indian cultures and histories in the statutory definition of a quality education. Consequently, P-16 educators have legal obligations, ethical commitments, and instructional responsibilities to educate all Montanans about the state's first inhabitants. Since no other state in the United States has a comparable constitutional mandate, IEFA 
serves as a model for all educators dedicated to embracing ideals of social justice and educational equity.

In this essay, we summarize the IEFA professional development opportunities Dr. Jioanna Carjuzaa, the lead author, has provided to faculty at Montana State University (MSU) and highlight the journey of Dr. Holly Hunts, a professor in the College of Education Health and Human Development. Holly teaches courses in Family Consumer Sciences (FCS) and, through participation in several IEFA workshops, has chosen to extend the long-standing professional boundaries of her discipline to include American Indian perspectives. Her journey to integrate IEFA in a culturally responsive manner dispels the myth that content knowledge is diminished by making room for other perspectives. Instead of limiting the transmission of ideas, expanding the boundaries has opened a floodgate to new information and other ways of knowing for Holly and her students. As the director of IEFA, I (Jioanna) collected data from informal communications, surveys, and workshop feedback. The data suggest that integrating IEFA across the curriculum in a culturally responsive manner is a challenging task for many faculty members who feel inadequately prepared to do so. From my experience leading educators on this journey, it is clear they need handholding while exploring how to create meaningful lessons since faculty are likely to have had minimal exposure to culturally responsive pedagogy as an approach and lack a clear understanding of the requirements of IEFA. Holly, like other faculty, needed specific instruction on the benefits and goals of culturally responsive pedagogy, an overview of the chronology of this landmark legislation and practice in applying the Seven Essential Understandings (OPI, 2001) that serve as a framework for what Indigenous knowledge is to be integrated as well as appropriate, authentic materials and resources to use.

\section{IEFA Professional Development Workshops}

Over the past seven years I (Jioanna) have facilitated 14 IEFA workshops. After administering an initial survey to faculty in the teacher preparation program to find out where we stood collectively as a department and what knowledge individuals had about IEFA, I scheduled the first workshop to bring teacher educators from across the state together to share best practices. With a generous grant from OPI, we were able to invite participants from the Tribal Colleges, the institutions in the Montana University System, and the private colleges for a two-day institute and to purchase a variety of IEFA resources to distribute. After the statewide workshop, each institution was encouraged to organize a professional development workshop for their faculty. For MSU's initial workshop, we explored the IEFA mandate and how it affects higher education.

I have been granted numerous awards that allowed me to offer subsequent workshops. They included providing instruction in social justice and culturally responsive pedagogy, asking interested educators to develop lesson plans they could integrate into their curricula, and sharing their findings in a poster session. Other workshops have included a 'gallery walk', presentations by leading Indian educators such as Dr. Henrietta Mann and Tribal College Presidents, a multimedia presentation on Indian stereotypes by an Oscar winner, and, most recently, a workshop dispelling the myths and misconceptions surrounding the first Thanksgiving where a Wampanoag spiritual leader shared his perspective.

To address the concerns and fears Holly expressed in the opening quote and those that other colleagues have shared with me about designing a culturally responsive IEFA lesson plan, I have carefully choreographed the phases of the professional development workshops to scaffold their learning. Feedback from participants in attendance at the workshops indicates that they enjoy meeting American Indian educators and other tribal members, appreciate the access to numerous resources and materials, and benefit from exposure to content-specific Indigenous knowledge as well as strategies for integrating IEFA.

\section{Challenges to Implementation}

Even though all Montana educators have a constitutional obligation to integrate IEFA, some faculty in higher education feel a natural fit to their discipline, while others struggle to find logical connections. The resistance I have observed usually results from both a misunderstanding of the goals of IEFA and fear. Some educators voice their concern about what they perceive as an unfair bias when the focus is put on American Indians. Some instructors question why we focus on American Indians if diversity is 
the goal. Bobbi Ann Starnes (2006), a former reservation classroom teacher offered this explanation:

Whether or not there are large numbers of Native Americans or reservations in every region of the country, Indian Education for All underscores a national challenge to our education system to improve our teaching about Native American history and culture more evident than during the month of November. (p. 186)

\section{Blame shame guilt}

According to Cleary and Peacock (1998), as is the case with many minority groups in the United States, American Indians are often inaccurately portrayed and their contributions are inadequately represented. Until IEFA was funded, quality curriculum and resources about and by American Indians were scarce. When talking about the forced assimilation, the cultural genocide, and the deplorable abuses in the boarding schools, many educators react as Holly did: "I am ashamed of being white and feel guilty because I am an American." She described the dread she felt when she was obliged to attend a faculty meeting prior to my workshop series on IEFA. She had this to say about that early experience:

\begin{abstract}
Unfortunately, with my childhood ideas about American Indians long set aside, eight years ago I found myself at a university faculty meeting about American Indians. I knew that there would be a speaker who would relate one horrific story after another about inhumane atrocities perpetrated by the U.S. government and inflicted on American Indians. I knew the stories were coming because I had been to several, nearly identical, meetings over the years.
\end{abstract}

\section{You cannot teach what you don't know}

Faculty members are often disturbed and shocked to discover that in their K-12 educations and college courses several 'inconvenient truths' were never broached. Among faculty there is a shared all-too-common journey (Carjuzaa,
2009; Juneau, 2006). For too many generations, Indian and non-Indian students alike have graduated from their respective schools having learned virtually nothing about American Indians. Consequently, faculty members are not inclined to include Indian content in their courses. Holly shared,

As I think about it, this must have been the same strategy taken by generations of professors in my field. As an undergraduate and graduate student, I cannot recall a single time a professor mentioned American Indians. As a professional, in my field, I had never read a research paper or seen a conference presentation about American Indians. I certainly had never met an American Indian in my field. American Indians did not seem central to my discipline.

\section{First attempt at integration}

After attending several IEFA professional development workshops, Holly decided to ask her FCS Methods students to create a unit plan; then they put together a presentation for in-service FCS teachers statewide. One group created lesson plans on Star Quilts and explained how the loss of the buffalo and the internment of Indians on reservations led to quilting. Another group of students taught about the health benefits of native foods found in Montana and the holistic qualities of medicine wheels. Still another group taught about storytelling as a means of transferring knowledge and created tribal specific bookmarks with basic vocabulary in several Indigenous languages (i.e., numbers, colors, shapes, animals, simple nouns).

At an IEFA Best Practices conference, Holly was invited to present her students' work. She was worried since both Indian and non-Indian educators were in attendance. It turns out there were several unintentional errors in her students' lessons. Like so many faculty members who are experts in their respective disciplines, dabbling in an area where they are neophytes can be daunting. Holly shared,

I fixed the errors and am still here to tell my story ... most people applauded that I made an effort. I gained some 
confidence that I could teach something about American Indians, although it was evident that future work should include more thorough research. I became determined to find and tell the truth about American Indians.

Holly's attempt illustrates how important it is to learn from our mistakes and move forward. Her perseverance, inquisitiveness, and humility were admirable.

\section{Working through cognitive disequilibrium}

When an educator has always presented material from a Western paradigm exclusively as if it were the universal truth, including multiple perspectives in one's teaching is challenging. Holly found this to be the case when she wanted to present a more authentic First Thanksgiving. In the beginning, Holly confessed that she did not ever consider questioning the Thanksgiving story - she just looked for historically accurate foods and recipes. Since she had known the Thanksgiving story for as long as she could remember and everyone she knew confirmed the same story, she had never considered that the Wampanoag perspective could be different. Holly shared this description of the holiday:

In 1621, the Pilgrims travelled from England on the Mayflower seeking religious freedom. They were the first white people the Wampanoag people had ever met. One fall day, in celebration of their large harvest, the Pilgrims invited the Wampanoag Indians to a feast known as the first Thanksgiving. The pilgrims gave thanks to God and to the Indians for their successful year of harvest.

\section{Changing curriculum to be inclusive of multiple perspectives}

Holly was sure that the story was right. She was not sure quite how she knew it was true, but she definitely knew it was true. To her surprise, research proved that the story was almost entirely incorrect. Once Holly relearned the First Thanksgiving, she was able to address some of the myths that she had perpetuated with her students. They watched clips from We Shall Remain and 500 Nations, and read numerous accounts from the Indians' point of view. Holly shared this realization regarding what she uncovered about the First Thanksgiving,

My students and I organized an 'authentic' Thanksgiving dinner for 4-H youth and their families. I knew that it was silly to think that turkey, stuffing, mashed potatoes, gravy, rolls and pumpkin pies were really a 400 year old tradition. I thought that the authentic Thanksgiving menu was going to be the big revelation for my students and the 4-Hers. What I did not count on, was learning that the Thanksgiving menu was the very least of major misinformation about Thanksgiving.

\section{Taking a cultural plunge}

Holly decided to step outside of her comfort zone and take a cultural plunge (Carjuzaa, 2007). She applied for a three day guided tour of the Crow Reservation to learn about the Battle of the Little Bighorn. She hoped that she would learn the 'truth' by actually being on-site. It was a trip designed to lead to multiple perspective understandings. Before leaving home, she was required to read Killing Custer, written by a respected member of the Blackfeet tribe. With the book read, she toured the Little Bighorn Battle National Monument with the help of a Sioux guide. The guide's version of the battle's events was markedly different from that of the book. Leaving the monument, they traveled to an elaborate re-enactment of the battle as choreographed by a Crow family, which was significantly different from the versions of the battle she had read and seen. Later that same day she watched a film, and found that the film had its own variation of events. The next day she listened to speakers from a variety of tribes, including the author of the book they had read, and Holly reaffirmed, there are always multiple truths.

\section{In need of an action plan}

Eight years ago, Holly confessed to being defensive and feeling guilty, ashamed and embarrassed by her ignorance of American Indians, and she thought silence seemed like the only rational, neutral action. However, as she 
discovered, silence is not neutral. Silence means that one is knowingly letting myths and misconceptions perpetuate. It supports 'conferred dominance.' Holly shared, "It took me a long time to realize that silence in the classroom, was at the core of ignorance and that ignorance was at the core of racism. When I was silent, I was not being part of the solution, I was promoting ignorance." After participating in several IEFA professional development workshops, Holly is more confident and has an action plan that is straightforward and doable:

All I need to do is to encourage students to seek multiple truths including truths from American Indian perspectives. I do not need to know all of the truths. My role is just to keep asking questions like: How do you 'know' something is true? Could it be that what you 'know' is just one dimension of a truth that is multidimensional?

\section{Conclusion}

Indian Education for All exemplifies the shared tenets of multicultural education theorists and the practice of culturally responsive pedagogy; it also addresses the historical and contemporary oppression of Indigenous peoples by transforming educational policy, curriculum, and pedagogy. By sharing our professional development offerings and highlighting Holly's journey, we demonstrate how IEFA reaches beyond Montana's borders with a hopeful example, inspiring educators worldwide to become more culturally inclusive in their classrooms and cross discipline boundaries to enrich their teaching.

Educators need to acquire background knowledge, build confidence, make connections with tribal members, review and incorporate Indian content, and learn instructional strategies that complement the implementation of culturally relevant pedagogy in order to teach their students about the unique histories and cultures of Montana Indians. Faculty committed to this process, like Holly, need support in order to be successful. According to Banks and Banks (1997), our challenge is to create an education that will help foster a just and inclusive pluralistic national society that all students and groups will perceive as legitimate" (p.14).

\section{References}

Banks, J.A., \& Banks, C.A.M. (1997). Multicultural education: Issues and perspectives. ( ${ }^{\text {rd }}$ ed.) Boston: Allyn and Bacon.

Cleary, L.M. \& Peacock, T.D. (1998). Collected wisdom: American Indian education. Upper Saddle River, NJ: Pearson Education.

Carjuzaa, J. (2007). Cultural plunges: Pre-service teachers confront unacknowledged biases. The International Journal of Diversity in Organisations, Communities and Nations, 7(5), 153-160.

Carjuzaa, J. (2009). Professional development for teacher educators to help them prepare their teacher candidates to integrate Montana's Indian Education for All Act across the K-12 curriculum. International Online Journal of Educational Sciences, 1(1), 29-47.

Juneau, D. (2006). Montana's agenda: Issues shaping our state, Indian Education for All. The University of Montana Press.

Office of Public Instruction [OPI], Indian Education Division. (2001). Essential understandings regarding Montana Indians. Retrieved from www.opi.mt.gov/pdf/indianed/resources/ essentialunderstandings.pdf

Office of Public Instruction [OPI], Indian Education Division. (2010). Montana American Indian student achievement data report Fall 2010. Retrieved from http://www.opi.mt.gov/pdf/IndianEd/HotTopics/ 10IndianEdStudentDataRpt.pdf

Starnes, B.A. (2006). Montana's Indian Education for All: Toward an education worthy of American ideals. Phi Delta Kappan, 88(3), 184-192.

\section{Biographies}

Jioanna Carjuzaa is an Associate Professor in the 
Department of Education at Montana State UniversityBozeman where she teaches multiple sections of Multicultural Foundations of Education, in addition to offering graduate courses in Social Justice in Education, American Indian Studies for Teachers, Indigenous Research Methodologies, and Culturally Responsive Pedagogy in Practice. She serves as co-advisor to the American Indian Council and as the facilitator for Indian Education for All professional development opportunities for MSU faculty, staff, and students.

Holly Hunts is an Associate Professor in the Department of Health and Human Development at Montana State University-Bozeman. Her current responsibilities at MSU include serving as the program leader for Family and Consumer Sciences Teacher Education and teaching a wide variety of courses. Her research is focused on innovative teaching techniques in FCS, Indian Education for All, and service learning. Her specialties and interests include: family/consumer economics, 4-H Foods Project, autism as a consumer issue, and national standards and exams for FCS teachers. 